January 2003

\title{
Age, temperature, and parasitaemia predict chloroquine treatment failure and anaemia in children with uncomplicated Plasmodium falciparum malaria
}

D.H. Hamer

Boston University School of Public Health

W.B. MacLeod

Boston University School of Public Health

E. Addo-Yobo

Komfo Anokye Teaching Hospital

C.P Duggan

Children's Hospital, Boston

B. Estrella

Corporación Ecuatoriana de Biotecnología

See next page for additional authors

Follow this and additional works at: http://ecommons.aku.edu/eastafrica_fhs_mc_pathol

Part of the Pathology Commons

\section{Recommended Citation}

Hamer, D., MacLeod, W., Addo-Yobo, E., Duggan, C., Estrella, B., Fawzi, W., Konde-Lule, J., Mwanakasale, V., Premji, Z., Sempertegui, F., Ssengooba, F., Yeboah-Antwi, K., Simon, J. (2003). Age, temperature, and parasitaemia predict chloroquine treatment failure and anaemia in children with uncomplicated Plasmodium falciparum malaria. Transactions of the Royal Society of Tropical Medicine and Hygiene, 97(4), 422-428.

Available at: http://ecommons.aku.edu/eastafrica_fhs_mc_pathol/82 
Authors

D.H. Hamer, W.B. MacLeod, E. Addo-Yobo, C.P Duggan, B. Estrella, W.W. Fawzi, J.K. Konde-Lule, V. Mwanakasale, Zul Premji, F. Sempertegui, F.P. Ssengooba, K. Yeboah-Antwi, and J.L. Simon 


\title{
Age, temperature, and parasitaemia predict chloroquine treatment failure and anaemia in children with uncomplicated Plasmodium falciparum malaria
}

\author{
D. H. Hamer 1,2,3,4, W. B. MacLeod ${ }^{1}$, E. Addo-Yobo ${ }^{5}$, C. P. Duggan 6 , B. Estrella ${ }^{7}$ W. W. Fawzi ${ }^{8}$ \\ J. K. Konde-Lule', V. Mwanakasale ${ }^{10}$, Z. G. Premji ${ }^{11}$, F. Sempértegui ${ }^{7}$, F. P. Ssengooba ${ }^{9}$, \\ K. Yeboah-Antwi ${ }^{12}$ and J. L. Simon ${ }^{1}{ }^{1}$ Center for International Health and Development, Boston University School of \\ Public Health, Boston, MA, USA, ${ }^{2}$ Division of Geographic Medicine and Infectious Diseases, New England Medical Center, \\ Boston, MA, USA; ${ }^{3}$ Department of Medicine, Tufts University School of Medicine, Boston, MA, USA; ${ }^{4}$ Tufts University \\ Gerald F. and Dorothy R. Friedman School of Nutrition Science and Policy, Boston, MA, USA; Komfo Anokye Teaching \\ Hospital, Kumasi, Ghana; 'Division of Gastroenterology and Nutrition, Children's Hospital, Boston, MA, USA; \\ ${ }^{7}$ Corporación Ecuatoriana de Biotecnologia, Quito, Ecuador; ${ }^{8}$ Departments of Nutrition and Epidemiology, Harvard School \\ of Public Health, Boston, MA, USA; ${ }^{9}$ Institute of Public Health, Kampala, Uganda; ${ }^{10}$ Tropical Diseases Research Centre, \\ Ndola, Zambia; ${ }^{11}$ Muhimbili University College of Health Sciences, Dar es Salaam, Tanzania; ${ }^{12}$ Malaria Consortium, \\ Accra, Ghano
}

\begin{abstract}
The prevalence of chloroquine-resistant Plasmodium falciparum malaria has been increasing in subSaharan Africa and parts of South America over the last 2 decades, and has been associated with increased anaemia-associated morbidity and higher mortality rates. Prospectively collected clinical and parasitological data from a multicentre study of 788 children aged 6-59 months with uncomplicated $P$. falciparum malaria were analysed in order to identify risk factors for chloroquine treatment failure and to assess its impact on anaemia after therapy. The proportion of chloroquine treatment failures (combined early and late treatment failures) was higher in the central-eastern African countries (Tanzania, 53\%; Uganda, 80\%; Zambia, 57\%) and Ecuador (54\%) than in Ghana (36\%). Using logistic regression, predictors of early treatment failure included younger age, higher baseline temperature, and greater levels of parasitaemia. We conclude that younger age, higher initial temperature, and higher baseline parasitaemia predict early treatment failure and a higher probability of worsening anaemia between admission and days 7 or 14 post-treatment.
\end{abstract}

Keywords: malaria, Plasmodium falciparum, anaemia, chloroquine, treatment failure, Africa, Ecuador

\section{Introduction}

Plasmodium falciparum malaria is a major cause of morbidity and mortality worldwide, especially in subSaharan Africa. Levels of chloroquine resistance have steadily increased over the last 2 decades in Africa (Khan \& Macguire, 1978; Brandling-Bennett et al., 1988; Watkins et al., 1988; Premji et al., 1994; Bloland et al., 1998; Makono \& Sibanda, 1999) and in some areas of South America (Blair-Trujillo et al., 2002; Marquiño et al., 2003). The continued use of chloroquine as first-line therapy for malaria increases the risk of anaemia and the need for blood transfusions in young children (Greenberg et al., 1989; Ekvall et al., 1998; McElroy et al., 2000). In Africa, chloroquine resistance has been associated with increased mortality, particularly in children aged $<5$ years (Zucker et al., 1996; Trape et al., 1998).

Effective treatment of malaria reduces the risk of death in children with severe anaemia (Zucker et al., 1996). In a community-based study of Tanzanian children, early treatment failure (ETF) with chloroquine was associated with a greater decrease in haemoglobin $(\mathrm{Hb})$ level after $72 \mathrm{~h}$ than late treatment failure (LTF) or adequate clinical response (ACR). Despite ACR to chloroquine, no improvement in $\mathrm{Hb}$ levels was seen during follow-up greater than $21 \mathrm{~d}$ after initial therapy. In contrast, treatment with sulfadoxine-pyrimethamine (SP) resulted in significant improvement in $\mathrm{Hb}$ levels (Ekvall et al., 1998).

Despite rising levels of resistance, chloroquine continues to be the antimalarial treatment of choice in many countries, because it is well tolerated, safe, inexpensive, and highly effective against susceptible strains of $P$. falciparum. Treatment with chloroquine often leads to rapid symptomatic improvement in

Address for correspondence: Davidson H. Hamer, Applied Research on Child Health Project, Center for International Health, Department of International Health, Boston University School of Public Health, 715 Albany Street, T4w, Boston, MA 02118, USA; phone +1 6174141267 , fax +1 617414 1261, e-mail dhamer@bu.edu patients with malaria despite failure of the drug to clear parasites from the blood (Hoffman et al., 1984; Khoromana et al., 1986; Brandling-Bennett et al. 1988). Given the lack of inexpensive, non-toxic, and effective alternatives, the continued use of chloroquine in countries or regions with lower levels of resistance seems to be a reasonable approach until a better alternative becomes available and affordable.

In a study of children with uncomplicated $P$. falciparum malaria, conducted in the Solomon Islands, independent risk factors for chloroquine resistance included young age, high parasite density, normal spleen size, malnutrition, and the presence of gametocytes in thick films (Hess et al., 1996). Using multivariate analysis, a recent study in Uganda found that age $<5$ years, presenting temperature $>38.0^{\circ} \mathrm{C}$, and chloroquine use 3-4 d before study entry were independent predictors of chloroquine treatment failure (Dorsey et al., 2000). While other studies have attempted to define risk factors for chloroquine treatment failure, methodological differences, small sample size, and failure to control for potentially confounding effects serve to limit the strength of their results (Brandling-Bennett et al., 1988; Henry et al., 1994, 1996; Alene \& Bennett, 1996; Ekvall et al., 1998). In addition, most studies have focused on only 1 country.

During the course of a randomized, placebocontrolled, multicentre trial of zinc as an adjunct to the treatment of acute, uncomplicated $P$. falciparum malaria in young children, data were prospectively collected on ETF and LTF with chloroquine (ZAP, 2002). This paper characterizes and contrasts chloroquine resistance in vivo in the 5 participating study sites and attempts to identify independent risk factors for chloroquine treatment failure and persistent anaemia after an episode of malaria.

\section{Methods}

Full details concerning the study design and methods can be found elsewhere (ZAP, 2002). In order to ensure uniformity of data collection across study sites, we used a common protocol, a detailed study 
procedure manual, pilot studies at each site, and technical site visits at the beginning of enrolment in order to assess and ensure uniformity of study procedures. Special quality control measures were used to ensure consistency in the performance and interpretation of blood films among the study sites. Internal quality control consisted of duplicate reading of a $10 \% \mathrm{sub}-$ sample of smears by an experienced parasitologist at each site. while external quality control was done on a $5 \%$ sample of slides from all sites by an experienced parasitologist (Z. G. P.).

Study sites

Subject enrolment took place between December 1998 and May 2000 at the following locations: Hospital Delfina Torres (Esmeraldas, Ecuador), Komfo Anokye Teaching Hospital (Kumasi, Ghana), Kisarawe District Hospital (Kisarawe, Tanzania), Mpigi Health Center (Mpigi, Uganda), and Arthur Davison Children Hospital (Ndola, Zambia). These sites represent a mixture of urban and rural populations in Africa and Latin America. The 4 African sites are in malaria hyperholoendemic zones whereas the Ecuadorian site is in a hypoendemic zone.

\section{Study subjects}

Children aged 6-59 months with axillary temperature $\geqslant 37.5^{\circ} \mathrm{C}$ and $\geqslant 2000 / \mathrm{mm}^{3}$ asexual forms of $P$. falciparum in a thick blood film were eligible for participation in the study. Exclusion criteria included: $\mathrm{Hb}<70 \mathrm{~g} / \mathrm{L}$, severe malaria as defined by WHO (1990), non-P. falciparum or mixed Plasmodium infections, concurrent severe infections (i.e. lower respiratory infection, acute otitis media, pyelonephritis, typhoid fever, bloody diarrhoea, meningitis, or measles), severe dehydration, malnutrition as defined by the Wellcome criteria (Anonymous, 1970), inability to tolerate oral medications or fluids, chronic illness, and prior participation in the trial. Written informed consent was obtained from the child's parent or carer. The institutional review boards at each site and the Harvard School of Public Health, Boston, MA, USA, approved the study.

Once enrolled, children were admitted to an inpatient ward for $48-72 \mathrm{~h}$. Demographic data, use of antivector measures to prevent malaria, recent antimalarial use, and significant past medical history were collected. A complete physical examination was performed at the time of study entry and daily during hospitalization and as clinically indicated. Axillary temperature was measured every $4 \mathrm{~h}$. Paracetamol was administered for temperatures $\geqslant 38.5^{\circ} \mathrm{C}$ every $6 \mathrm{~h}$ at a dose of $10-15 \mathrm{mg} / \mathrm{kg}$.

\section{Antimalarial treatment and follow-up}

Chloroquine was the recommended first-line drug for the treatment of malaria in all 5 countries during the study period. The following dosing schedule was used: $10 \mathrm{mg} / \mathrm{kg}$ on day $0,10 \mathrm{mg} / \mathrm{kg}$ on day 1 , and $5 \mathrm{mg} / \mathrm{kg}$ on day 2 . If either a treatment or parasitological failure occurred (see outcome classifications for definitions), treatment with a standard dose of either amodiaquine or SP (Fansidar, Roche, Zurich, Switzerland) was administered. Quinine was used for the treatment of children who developed severe malaria (WHO, 1990). Children with symptomatic severe anaemia were transfused with packed red blood cells. Discharge from hospital occurred once the fever had resolved (axillary temperature $<37.5^{\circ} \mathrm{C}$ for at least 12 h) and there was $a \geqslant 75 \%$ reduction of parasitaemia relative to baseline.

Children were seen at follow-up at the health centre on days 7,14 , and 28 . If the patient did not return for follow-up, a research assistant went to the subject's house to locate the patient. At each follow-up visit, a history of fever during the last week and recent anti- malarial drug use were collected, blood smears were performed, and $\mathrm{Hb}$ was measured.

\section{Laboratory tests}

Giemsa-stained thick blood films were prepared at the time of enrolment, at $24 \mathrm{~h}, 36 \mathrm{~h}, 48 \mathrm{~h}, 72 \mathrm{~h}$, and at days 7,14 , and 28 . Total parasite count per microlitre was quantitated by counting the number of parasites per 200 white blood cells (WBC), assuming a total WBC count of $8000 / \mu \mathrm{L}$ (Trape, 1985). A thick film was declared negative after viewing high power fields containing 500 WBCs. The $\mathrm{Hb}$ concentration was determined by HemoCue (Angelholm, Sweden) on admission and on days 7,14 , and 28 .

\section{Outcome classification}

Therapeutic response was defined using a modified version of the WHO 14-day in vivo clinical classification system (WHO, 1996; Table 1). The definition of LTF was modified as follows. Because axillary temperatures were not taken during follow-up home visits, we used a history of fever during the last week instead of axillary temperature and history of fever in the previous $48 \mathrm{~h}$. We also used a history of hospitalization with parasitaemia in place of severe malaria/danger signs with parasitaemia. The response to chloroquine treatment was also classified according to the WHO parasitological classification system (WHO, 1973; Table 1).

\section{Data management and statistical methods}

Data entry and management was carried out using Epi-Info, version 6.04c (CDC, Atlanta, GA, USA) and Integrated Microcomputer Processing System, version 3.1 (US Bureau of Census, Washington, D.C., USA). Since there was no effect of the zinc supplement on clinical, parasitological, or haematological outcomes (ZAP, 2002), the 2 treatment groups were combined for the purposes of this analysis.

Statistical analyses were carried out using SAS, version 8.2 (SAS Institute Inc., Cary, NC, USA). Odds ratios and $95 \%$ CIs were predicted from logistic regression parameter estimates and Wald confidence intervals. Multiple logistic regression models for predictors of ACR, ETF, and LTF created models that initially included study site, age in months, use of bednets, initial temperature, log-transformed baseline parasitaemia, baseline $\mathrm{Hb}$, gender, use of personal antimosquito control, use of antimalarials in the previous $7 \mathrm{~d}$, breastfeeding, mother literate, weight-for-age $Z$-score, height-for-age $Z$-score, and whether the subject was randomized to receive zinc.

Predicators of $\mathrm{Hb}$ change were modelled with multivariate, repeated measures analysis of variance (ANOVA). The model initially included an indicator variable for ACR, study site, age in months, use of bednets, initial temperature, log-transformed baseline parasitaemia, gender, use of personal antimosquito control, use of antimalarials in the previous $7 \mathrm{~d}$, breastfeeding, mother literate, weight-for-age $Z$-score, height-for-age $Z$-score, and whether the subject was randomized to receive zinc.

Both final models were constructed using a backwards elimination selection process and these models were confirmed with a forward selection process. All models included indicator variables for study site. Two-way interactions of statistically significant main effects were tested.

\section{Results}

Baseline characteristics

One thousand and eighty-seven children were enrolled. The analytical data set consisted of the 788 children for whom complete clinical and parasitological data were available. Baseline characteristics of the study participants, broken down by site of enrolment, are 
Table 1. Definitions of clinical and parasitological outcomes in study children with uncomplicated Plasmodium falcipamum malaria

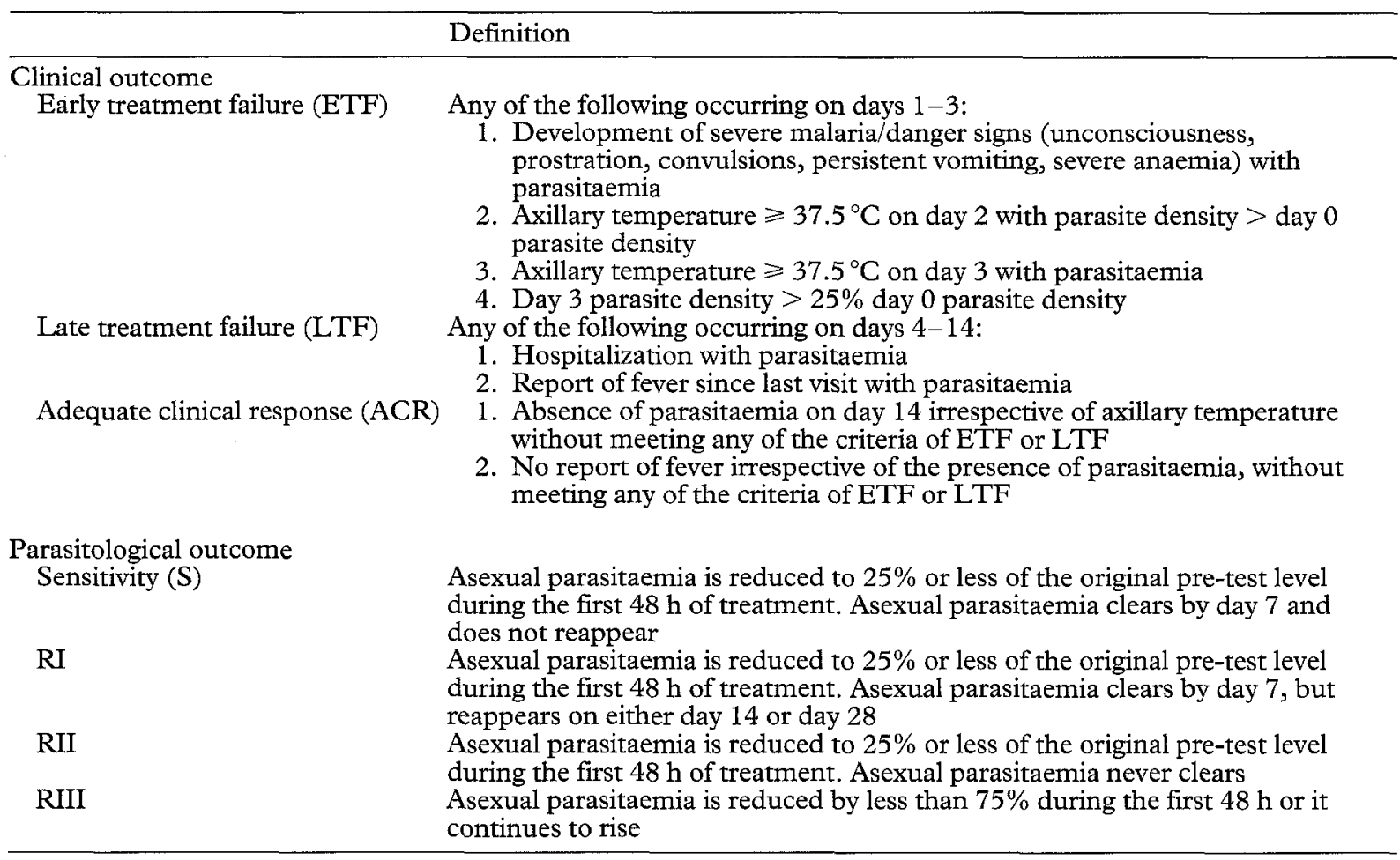

displayed in Table 2. We compared the baseline demographic, clinical, and parasitological characteristics of the group of children who were excluded from analysis with the group for whom we had complete data, and found few differences. There was greater bednet use in the group with complete data. Subjects in Ecuador tended to be older (mean age 39.2 months) than those in the African sites (mean age 25.4 months) and had significantly lower geometric mean parasite counts (9450 vs. $19930 / \mu \mathrm{L})$. Lastly, children in Uganda had a lower mean height-for-age $Z$-score.

The children enrolled from Tanzania and Zambia had higher levels of parasitaemia than those from Ghana, Uganda, or Ecuador. Baseline $\mathrm{Hb}$ levels and bednet use varied widely across sites. The reported use of antimalarials in the week before hospitalization varied from $17 \%$ in Ecuador to $54 \%$ in Uganda. Chloroquine was by far the most commonly used antimalarial overall ( $92 \%$ overall).

\section{Clinical and parasitological outcomes}

Chloroquine treatment failures were common in Central-East Africa and Ecuador with ETFs ranging from 38 to $65 \%$. Significantly more children in Ghana had ACRs than children in the other 4 countries combined $(P<0.0001)$. Parasitological resistance results are displayed in Table 3. Combined RII and RIII resistance was $>50 \%$ in all countries except Ghana $(48.7 \%)$. A moderate number of discordant results were encountered when parasitological resistance rates were compared with ETF and LTF (Table 4). We combined S and RI (which are closest to the definition of ACR) and computed a $\kappa$ statistic to compare the concordance between the 2 classification systems. The agreement between the 2 systems was $67 \%$ and had a $\kappa$ coefficient of $0.48(P<0.0001)$.

ETF occurred in $17.1 \%(48 / 280)$ of children with RI or S parasitological outcomes. Although there appeared to be discordance between the presence of RIII parasitological resistance and an ACR in 52 children, this discrepancy proved to be a result of how RIII was defined. All 52 children failed to have a reduction to $25 \%$ of baseline parasitaemia by $48 \mathrm{~h}$ (therefore meeting the definition of RIII) but, by $72 \mathrm{~h}$, parasitaemia had dropped below $25 \%$ (thus not fulfilling the criteria for ETF). Surprisingly, $20.2 \%(68 / 337)$ of children with ACRs had RII resistance.

\section{Predictors of treatment failure}

Logistic regression analysis was used to identify possible predictors of chloroquine treatment failure (combined ETF and LTF). Univariate predictors of ETF included younger age, increased temperature at baseline, higher parasitaemia at presentation, and current breastfeeding. Gender, zinc treatment, bednet use, use of antivector measures, height-for-age $Z$-score, weightfor-age $Z$-score, baseline zinc plasma levels, and history of recent antimalarial therapy were not significantly associated with treatment failure. The risk of chloroquine treatment failure increased with decreasing age, higher baseline temperature, and greater density of baseline parasitaemia (Table 5). In the presence of the variable age, breastfeeding was not a predictor of treatment failure. A full model was fitted, controlling for study site, gender, zinc treatment, bednet use, use of antivector measures, height-for-age $Z$-score, weightfor-age $Z$-score, baseline zinc plasma levels, and history of recent antimalarial therapy. However, the inclusion of the additional terms had only minor impact on the odds ratios and $95 \%$ CIs.

\section{Haematological outcomes}

Most subjects $(84 \%)$ were anaemic $(\mathrm{Hb}<110 \mathrm{~g} / \mathrm{L})$ at baseline. In the overall study cohort, $\mathrm{Hb}$ levels declined between days 0 and day 7 from a mean of $92.6 \mathrm{~g} / \mathrm{L}$ to $87.2 \mathrm{~g} / \mathrm{L}$. Subsequently, the $\mathrm{Hb}$ concentration began to rise, reaching a mean of $95.5 \mathrm{~g} / \mathrm{L}$ at day 14 and $100.9 \mathrm{~g} / \mathrm{L}$ at day 28 . The final value at day 28 was a mean of $8.3 \mathrm{~g} / \mathrm{L}$, higher than at the time of presentation to the hospital. Children who had an ACR 


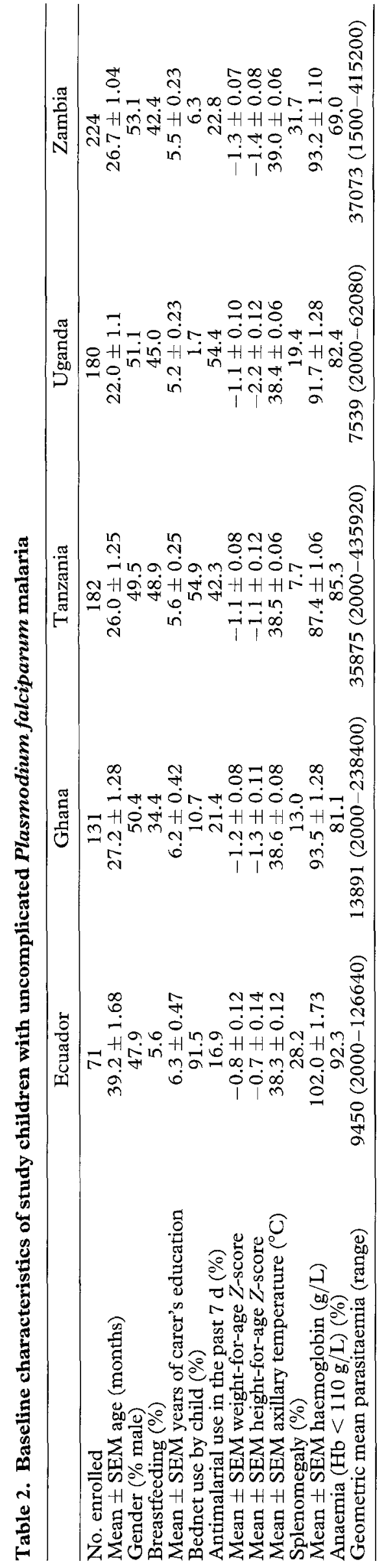

to chloroquine had significantly higher $\mathrm{Hb}$ concentrations at days $7(P<0.0001)$ and $14(P=0.0057)$ when compared with those with ETF or those with combined ETF and LTF (Figure). The day $28 \mathrm{Hb}$ level was higher in children who had an ACR but the difference was not statistically significant $(P=0.84)$.

Predictors of differences in haemoglobin from day 0 to 28

Risk factors for differences in $\mathrm{Hb}$ between the initiation of therapy and day 28 were identified using a repeated measures ANOVA. Predictors of differences in $\mathrm{Hb}$ included age $(P<0.0001)$, initial parasitaemia $(P=0.0004)$, and recent antimalarial therapy $(P=$ 0.0073 ) controlling for initial temperature, study site, gender, zinc treatment, bednet use, other antivector measure use, and ACR.

\section{Discussion}

Our study demonstrated high rates of chloroquine treatment failure in Ecuador, Tanzania, Uganda, and Zambia and moderate levels of resistance in Ghana. Only $20 \%$ of children in Uganda and less than half the children in Ecuador, Tanzania, and Zambia had an ACR to chloroquine. Although Ghanaian children had better clinical responses $(64.1 \%)$, the treatment failure rate was nonetheless above the $25 \%$ threshold recommended by the WHO for a change in national drug policy (WHO 1996).

The rate of resistance encountered in Uganda was higher than recently described. Dorsey et al. (2000) found a treatment failure rate of $47 \%$ compared with $80 \%$ in our study. One possible explanation is that the Dorsey study included adults who are more likely to have underlying antimalarial immunity. The ability to clear chloroquine-resistant parasites after treatment improves with age (Dijmbé et al., 2001).

The chloroquine resistance rates in Tanzania were similar to those that have been previously reported (Premji et al., 1994; Ekvall et al., 2001). Similarly, high rates of chloroquine treatment failures have also been described in Zambia (Barat et al., 1998). At the time that we carried out this study, the Ministries of Health of all of the 5 participating countries were still recommending the use of chloroquine as a first-line agent for the treatment of uncomplicated malaria in children. The results of our study provide further data to uphold the decisions that have subsequently been made by the Ministries of Health in Tanzania, Uganda, and Zambia to change from chloroquine as first-line therapy $(\mathrm{MoH}$, Tanzania, 1999; MoH, Uganda, 2001; MoH, Zambia, 2002). In Tanzania, although the Ministry of Health officially recommended discontinuing the use of chloroquine as the first-line drug, there continues to be extensive use of chloroquine in non-governmental health facilities and private practice associated with practitioner and community concerns about SP safety and cost. Similarly, in Zambia, although an official recommendation to change malaria drug policy has been made, the process of conversion to SP as an intermediate strategy prior to the introduction of artesunate-based combination therapy is proving to be logistically complicated. Thus, the findings of our study remain relevant to these countries.

The $\kappa$ coefficient of $48 \%$ represents a moderate agreement above chance between the 2 classification systems, indicating that we found a moderate level of discordance between the presence of parasitological resistance and clinical outcomes, especially when resistance was compared with ACRs. Some of this discrepancy might have stemmed from our relatively strict adherence to standard WHO definitions (WHO, 1973, 1996). Many children had evidence of RI or RII resistance but nevertheless had ACRs. Similar findings were noted in a study of chloroquine resistance in Mali in which children aged $<5$ years were more likely than older persons to have discordance between ACR and 
Table 3. Parasitological outcomes in study children with uncomplicated Plasmodium falciparum malaria

\begin{tabular}{lrcccr}
\hline Study site & No. & RIII (\%) & RII (\%) & RI (\%) & S (\%) \\
\hline Ecuador & 71 & 38.0 & 36.6 & 19.7 & 5.6 \\
Ghana & 131 & 22.1 & 26.7 & 20.6 & 30.5 \\
Tanzania & 182 & 36.3 & 20.3 & 23.6 & 19.8 \\
Uganda & 180 & 62.8 & 28.3 & 7.2 & 1.7 \\
Zambia & 224 & 39.3 & 16.1 & 24.1 & 20.5 \\
All Sites & 788 & 40.9 & 23.5 & 19.2 & 16.4 \\
\hline
\end{tabular}

Table 4. Comparison of clinical and parasitological outcomes in study children with uncomplicated Plasmodium falciparum malaria for all study sites

\begin{tabular}{lrrrrr}
\hline Outcome & RIII & RII & RI & S & Total \\
\hline Early treatment failure & 254 & 59 & 30 & 18 & 361 \\
Late treatment failure & 17 & 58 & 15 & 0 & 90 \\
Adequate clinical response & 52 & 68 & 106 & 111 & 337 \\
Total & 323 & 185 & 151 & 129 & 788 \\
\hline
\end{tabular}

Table 5. Multivariate regression analysis of risk of independent predictors of chloroquine treatment failure in study children with uncomplicated Plasmodium falciparum malaria controlling for study site

\begin{tabular}{lccc}
\hline Variable & Odds ratio & $95 \% \mathrm{CI}$ & $P$ \\
\hline Age per month increase & 0.97 & $0.96-0.98$ & $<0.0001$ \\
Temperature per $1{ }^{\circ} \mathrm{C}$ increase & 1.28 & $1.062-1.545$ & $<0.0098$ \\
Parasitaemia per 10 -fold increase & 1.21 & $1.07-1.36$ & 0.0019 \\
\hline
\end{tabular}

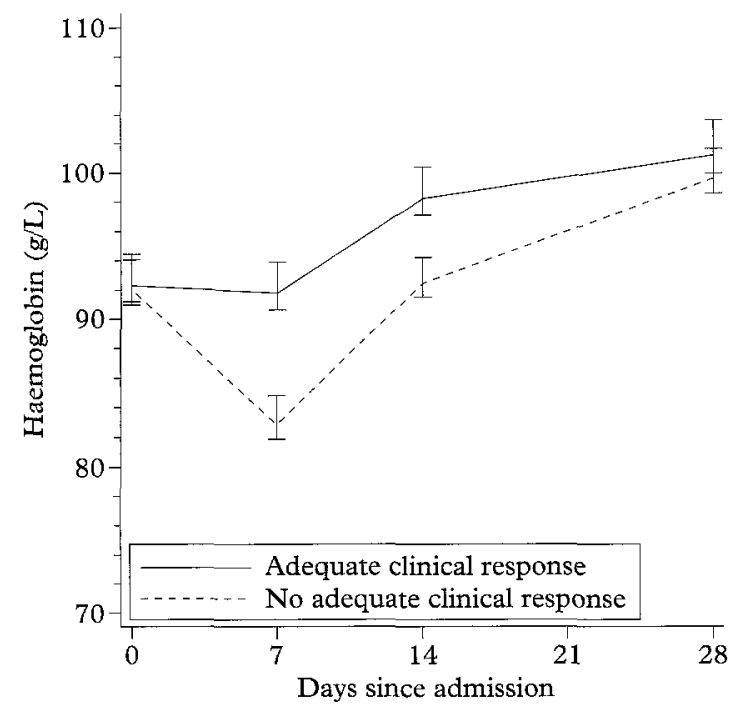

Figure. Mean haemoglobin concentration in study children with uncomplicated Plasmodium falcipamum malaria with and without adequate clinical response between days 0 and 28 . Error bars indicate $95 \% \mathrm{CI}$.

RI or RII resistance (Plowe et al., 2001). A recent study in Ghana also demonstrated this discordance (Ehrhardt et al., 2002). We encountered high rates of ETFs, which were usually associated with RII or RIII resistance. Only a small proportion of children had S or RI parasitological outcomes in the setting of early treatment failures. We also found that a small number of children with an ACR had RII or RIII resistance.
Although our results are substantially different from those of Plowe et al. (2001), this may have been due to the higher levels of parasitological resistance and treatment failures present at our study sites. In Plowe's report, younger children were more likely to have discordance between ACR and evidence of parasitological resistance (Plowe et al., 2001). Since our study population only included children aged $<5$ years, the greater degree of discordance between the parasitological resistance and therapeutic in vivo efficacy outcomes may have been largely due to the age range of our study population.

Younger age, higher temperature, and greater density of parasitaemia were independent predictors of chloroquine treatment failure in our study. Young age and high parasite density have been demonstrated in previous studies to be predictors of antimalarial drug resistance (Hess et al., 1996; Dorsey et al., 2000; Ehrhardt et al., 2002). A presenting temperature $>38^{\circ} \mathrm{C}$ was a predictor of treatment failure in Uganda (Dorsey et al., 2000). Our study also demonstrated that higher temperature was associated with an increased risk of chloroquine treatment failure. In addition, we demonstrated a progressive increase in the likelihood of treatment failure with rising temperature. A physiological explanation for the association between higher baseline temperature and risk of treatment failure is not apparent.

Recent antimalarial treatment, which was predominantly chloroquine, was not associated with an increased risk of treatment failure in our study. In contrast, Dorsey et al. (2000) found that patients who had taken chloroquine 3-14 d prior to study entry were more likely to be treatment failures when compared with patients who had not recently used chloroquine or who had been treated with chloroquine in the last $3 \mathrm{~d}$ (Dorsey et al., 2000). 
Two limitations of our study were the lack of urine testing for chloroquine and its metabolites and failure to define precisely when chloroquine was taken prior to presentation at the health centre. The majority of the carers of the children in our study denied recent antimalarial use. Previous studies have shown a high correlation between admitting to have taken an antimalarial and a positive urine test (Dorsey et al., 2000). However, the reliability of a patient's denial of recent antimalarial use is lower as many of these patients have detectable drug or metabolites in their urine (Dorsey et al., 2000). The lack of reliability of a negative report of recent antimalarial use complicates the interpretation of our data, which relied on carer recall. In addition, we did not ask the carers of the children in our study to define when antimalarials were taken. As a consequence, we cannot conclusively state that recent chloroquine use is not a risk factor for treatment failure. Since recent chloroquine use has been associated with parasitological resistance in other studies (Henry et al., 1996; Bayoumi et al., 1997), there appears to be a reasonable probability that this is also a predictor of treatment failure.

Another potential criticism of our study was our decision to not take temperatures at days 7 and 14 in accordance with WHO guidelines (WHO, 1996). We relied instead on a report of recent fever. A negative report of fever has been shown to have a high negative predictive value whereas a positive response is of questionable reliability (Einterz \& Bates, 1997, 1998; Verhoef et al., 1998). Not measuring temperature on days 7 and 14 should only have had an impact on the outcome, LTF. However, the independent risk factors for treatment failure in our cohort of children (young age, higher temperature, and higher parasite density) were most strongly associated with ETF. As a consequence, the use of recall data for recent fever is unlikely to have had a meaningful impact on our study findings.

Our entire study cohort was found to have worsening anaemia between baseline and day 7 with a gradual recovery of $\mathrm{Hb}$ over the following 3 weeks. Predictors of slower recovery of $\mathrm{Hb}$ in our study included younger age, higher presenting temperature, and greater parasite density. In children with ETF, there was a delayed recovery of $\mathrm{Hb}$ relative to those children who had ACRs. A recent study in Tanzania also found that children with ETF had a significantly greater decrease in $\mathrm{Hb}$ level at $72 \mathrm{~h}$ (Ekvall et al., 1998). However, in contrast to our study, which demonstrated a rise in $\mathrm{Hb}$ level by days 14 and 28 to levels that were higher than at the time of hospital presentation, the Tanzanian study found that all children who were treated with chloroquine did not recover to pre-treatment $\mathrm{Hb}$ levels. Differences in the dietary intake of iron, phytates, and the prevalence of concomitant parasitic infections (e.g. hookworm infections) are potential explanations for the difference between our results and those of the Tanzanian study.

The strengths of our study included a large sample size and the use of a consistent protocol with multiple quality control measures simultaneously in several different countries with varying degrees of transmission, with resultant variable underlying partial immunity of the population. The independent predictors of chloroquine treatment failure derived from our results and those of others (Hess et al., 1996; Ekvall et al., 1998; Dorsey et al, 2000) can be used to risk-stratify children who might benefit from immediate use of second-line antimalarials in countries with high levels of chloroquine resistance. Because of the clear association between treatment failure and delayed recovery from anaemia, the association between repeated episodes of malaria and anaemia, known negative impact of anaemia on physical activity and cognitive development in young children, and the need to reduce anaemia-associated blood transfusions in areas where hepatitis and
HIV are risks, countries that continue to use chloroquine in the face of treatment failure rates $>25 \%$ must carefully re-evaluate their first-line treatment policies.

\section{Acknowledgements}

This publication was made possible through support provided by the G/PHN/HN/CS, Global Bureau of the United States Agency for International Development under the terms of Cooperative Agreement No. HRN-A-00-96-90010-00. The opinions expressed herein are those of the authors and do not necessary reflect the views of the United States Agency for International Development.

\section{References}

Alene, G. D. \& Bennett, S. (1996). Chloroquine resistance of Plasmodium falciparum malaria in Ethiopia and Eritrea. Tropical Medicine and International Health, 1, 810-815.

Anonymous (1970). Classification of infantile malnutrition Lancet, ii, 302-303.

Barat, L. M., Himonga, B., Nkunika, S., Ettling, M., Ruebush, T. K. Kapelwa, W. \& Bloland, P. B. (1998). A systematic approach to the development of a rational malaria treatment policy in Zambia. Tropical Medicine and Intermational Health, 3, 543-552.

Bayoumi, R. A., Dar, F. K., Tanira, M. O. M., Stephen, R. S., Hussein, M. M., Hammo, N. E., Omer, R. I., Beidas, M. F., Shalabi, A. \& El-Wasila, M. (1997). Effect of previous chloroquine intake on in vivo $P$. falciparum drug sensitivity. East African Medical foumal, 74, 278-282.

Blair-Trujillo, S., Lacharme-Lora, L. \& Carmona-Fonseca, ] (2002). Resistance of Plasmodium falciparium to antimalarial drugs in Zaragoza 1998. Memorias do Instituto Oswaldo Cruz, 97, 401-406

Bloland, P. B., Kazembe, P. N., Oloo, A. J., Himonga, B. Barat, L. M. \& Ruebush, T. K. (1998). Chloroquine in Africa: critical assessment and recommendations for monitoring and evaluating chloroquine efficacy and treatment policy in sub-Saharan Africa. Tropical Medicine and International Health, 3, 543-552.

Brandling-Bennett, A. D., Oloo, A. J., Watkins, W. M. Boriga, D. A., Kariuki, D. H. \& Collins, W. E. (1988). Chloroquine treatment of falciparum malaria in an area of Kenya of intermediate chloroquine resistance. Transactions of the Royal Society of Tropical Medicine, 82, 833-837.

Djimbé, A., Duombo, O. K., Cortese, J. F., Kayentao, K., Soumbo, S., Diourté, Y., Dicko, A., Su, X. Z., Nomura, T. Fidock, D. A., Wellems, T. E. \& Plowe, C. V. (2001). A molecular marker for chloroquine-resistant falciparum malaria. New England fournal of Medicine, 344, 257-263.

Dorsey, G., Kamya, M. R., Ndeezi, G., Babirye, J. N., Phares, C. R., Olson, J. E., Katabira, E. T. \& Rosenthal, P. J. $(2000)$. Predictors of chloroquine treatment failure in children and adults with falciparum malaria in Kampala, Uganda. American Fournal of Tropical Medicine and Hygiene, 62 , $686-692$

Ehrhardt, S., Mockenhaupt, F. P., Agana-Nsiire, P., Mathieu, A., Anemana, S. D., Stark, K. Otchwemah, R. N. \& Bienzle, U. (2002). Efficacy of chloroquine in the treatment of uncomplicated Plasmodium falciparum malaria in northern Ghana. Annals of Tropical Medicine and Parasitology, 96, $239-247$.

Einterz, E. M. \& Bates, M. E. (1997). Fever in Africa: do patients know when they are hot? Lancet, 350, 781 .

Einterz, E. M. \& Bates, M. E. (1998). Author's reply. Lancet, 351, 373-374.

Ekvall, H., Premji, Z. \& Bjorkman, A. (1998). Chloroquine treatment failure for uncomplicated childhood malaria in an area with drug resistance: early treatment failure aggravates anaemia. Transactions of the Royal Society of Tropical Medicine and Hygiene, 92, 556-560.

Ekvall, H., Premji, Z., Bennett, S. \& Bjorkman, A. (2001) Hemoglobin concentration in children in a malaria holoendemic area is determined by cumulated Plasmodium falciparum parasite densities. American fournal of Tropical Medicine and Hygiene, 64, 58-66.

Greenberg, A. E., Ntumcanzondo, M., Ntula, N., Mawa, L., Howell, J. \& Davachi, F. (1989). Hospital-based surveilance of malaria-related paediatric morbidity and mortality in Kinshasa, Zaire. Bulletin of the World Health Organization, 67, 189-196.

Henry, M. C., Docters van Leeuwen, W., Watson, P., Jansen, A., Jacobs, K., Zwart, F. F., Agricola, K., Nahounou, N. Dossou, J. \& Eggelte, T. E. (1994). In vivo sensitivity of 
Plasmodium falcipamim to chloroquine in rural areas of Cote d'Ivoire. Acta Tropica, 58, 275-281.

Henry, M. C., Eggelte, T. A., Watson, P., Docters van Leeuwen, W. \& Kluin, J. (1996). Response of childhood malaria to chloroquine and Fansidar in an area of intermediate chloroquine resistance in Cote d'Ivoire. Tropical Medicine and International Health, 1, 610-615.

Hess, F. I., Iannuzzi, A., Leafasia, J., Cowdrey, D., Nothdurft, H. D., Von Sonnenburg, F., Löscher, T. \& Rieckmann, K. H. (1996). Risk factors of chloroquine resistance in Plasmodium falciparum malaria. Acta Tropica, 61, 293-306.

Hoffman, S. L., Masbar, S., Hussein, P. R., Soewarta, A., Harun, S., Marwoto, H. A., Campbell, J. R., Smrkovski, L., Purnomo \& Wiady, I. (1984). Absence of malaria mortality in villagers with chloroquine-resistant Plasmodium falciparum treated with chloroquine. Transactions of the Royal Society of Tropical Medicine and Hygiene, 78, 175-178.

Khan, A. A. \& Maguire M. J. (1978). Relative chloroquine resistance of $P$. falciparum in Zambia. British Medical fournal, 1, 1669-1670.

Khoromana, C. O., Campbell, C. C., Wirima, J. J. \& Heyman, D. L. (1986). In vivo efficacy of chloroquine treatment for Plasmodium falciparum in Malawian children under five years of age. American Fournal of Tropical Medicine and Hygiene, $35,465-471$.

Marquiño, W., MacArthur, J. R., Barat, L. M., Oblitas, F. E., Arrunátegui, M., Garavito, G., Chafloque, M. L., Pardavé, B., Gutierrez, S., Arróspide, N., Carrillo, C., Cabezas, C. \& Ruebush, T. K. II (2003) Efficacy of chloroquine, sulfadoxine-pyrimethamine, and mefloquine for the treatment of uncomplicated Plasmodium falciparum malaria on the north coast of Peru. American foumal of Tropical Medicine and Hygiene, 68, 120-123.

Makono, R. \& Sibanda, S. (1999). Review of the prevalence of malaria in Zimbabwe with specific reference to parasite drug resistance 1984-96. Transactions of the Royal Society of Tropical Medicine and Hygiene, 93, 449-452.

McElroy, P. D., Ter Kuile, F. O., Lal, A. A., Bloland, P. B. Hawley, W. A., Oloo, A. J., Monto, A. S., Meshnick, S. R. \& Nahlen, B. L. (2000). Effect of Plasmodium falciparum density on hemoglobin concentrations among full-term, normal birth weight children in western Kenya, IV. The Asembo Bay Cohort Project. American foumal of Tropical Medicine and Hygiene, 62, 504-512.

$\mathrm{MoH}$, Tanzania (1999). Implementation of a new antimalaria treatment policy in Tanzania: rationale for change and guide to the process of policy implementation. Ministry of Health Tanzania-Task Force Report. Tanzania Health Respiratory Bulletin, 2, 10-13.

MoH, Uganda (2001). Ministry of Health Consensus Meeting on Anti-Malarial Drug Policy in Kampala Uganda. Uganda: Ministry of Health, October 2001.

MoH, Zambia (2002). Antimalarial Drug Policy Strategic Framework Meeting. Lusaka: Ministry of Health, March 2002
Plowe, C. V., Doumbo, O. K., Diimde, A., Kayentao, K. Diourte, Y., Doumbo, S. N., Coulibaly, D., Thera, M. Wellems, T. E. \& Diallo, D. A. (2001). Chloroquine treatment of uncomplicated Plasmodium falciparum malaria in Mali: parasitologic resistance versus therapeutic efficacy. American fournal of Tropical Medicine and Hygiene, 64 $242-246$.

Premji, Z., Minjas, J. N. \& Shiff, C. J. (1994). Chloroquine resistant Plasmodium falciparum in coastal Tanzania: a challenge to the continued strategy of village based chemotherapy for malaria control. Tropical Medicine and Parasitology, 45, 47-48.

Trape, J. F. (1985). Rapid evaluation of malaria parasite density and standardization of thick smear examination for epidemiological investigations. Transactions of the Royal Society of Tropical Medicine and Hygiene, 79, 181-184.

Trape, J. F., Pison, G., Preziosi, M. P., Enel, C., Desgrées du Loû, A., Delaunay, V., Samb, B., Lagarde, E., Molez, J. F \& Simondon, F. (1998). Impact of chloroquine resistance on malaria mortality. Comptes Rendus de L'Academie des Sciences Paris Series III, 3, 689-697.

Verhoef, H., Hodgins, E., West, C. E., Carter, J. Y. \& Kok F. J. (1998). Diagnosis of fever in Africa. Lancet, 353, $372-373$.

Watkins, W. M., Percy, M., Crampton, J. M., Ward, S. Koech, D. \& Howells, R. E. (1988). The changing resistance of Plasmodium falciparum to antimalarial drugs in East Africa. Transactions of the Royal Society of Tropical Medicine and Hygiene, 82, 21-26.

WHO (1973). Chemotherapy of Malaria and Resistance to Antimalarials. Report of a WHO Scientific Group. Geneva, World Health Organization, Technical Report Series, No. 529.

WHO (1990). Severe and complicated malaria. Transactions of the Royal Society of Tropical Medicine, 84, supplement 2, pp. $1-6$.

WHO (1996). Assessment of Therapeutic Efficacy for Uncomplicated Falciparum Malaria in Areas with Intense Transmission. Geneva: World Health Organization, WHO/MAL/96.1077.

ZAP (Zinc Against Plasmodium Study Group) (2002). Effect of zinc on the treatment of Plasmodium falciparum malaria in children: a randomized, controlled trial. American fournal of Clinical Nutrition, 76, 805-812.

Zucker, J. R., Lackritz, E. M., Ruebush, T. K., Hightower, A. W., Adungosi, J. E., Were, J. B. O., Metchock, B. Patrick, E. \& Campbell, C. C. (1996). Childhood mortality during and after hospitalisation in western Kenya: effect of malaria treatment regimens. Transactions of the Royal Society of Tropical Medicine and Hygiene, 55, 655-660.

Received 30 September 2002; revised 11 February 2003; accepted for publication 11 February 2003

\section{Announcement}

\section{ROYAL SOCIETY OF TROPICAL MEDICINE AND HYGIENE Medal Award}

The Chalmers Medal is awarded each year in recognition of research contributing to the knowledge of tropical medicine or tropical hygiene. Only persons under the age of 46 on 1 June of the year of award shall be eligible. Nominations may be made by any Fellow of the Society, on forms available from the Society (50 Bedford Square, London WC1B 3DP, UK) or by e-mail (mail@,rstmh.org). Completed forms should be sent to the Honorary Secretaries by 30 September 2004. For full details of all Society medals, please refer to the website: www.rstmh.org 